\title{
Entornos del surrealismo en Xavier Villaurrutia: la poesía y el ensayo
}

\section{INTRODUCCION}

Las siguientes páginas quieren ser una contribución al estudio de la presencia e influencia del surrealismo en la literatura hispanoamericana, y en particular en su poesia. Su tema no es el surrealismo en esa literatura sino la gravitación que el «caso surrealista» ejerció de manera importante en una obra particular, y a partir de ello buscan hacer un examen de los rasgos visibles y fchacientemente emparentables con el surrealismo en esa muestra concreta. Su objeto de estudio: principalmente la poesia de Villaurrutia (México. 1903-1950), y en forma complementaria sus escritos ensayísticos.

Por razones de método, pero sobre todo por las condiciones históricas que rodearon el fenómeno que aqui asi se aborda, el título de estas páginas hace referencia a los "entornos de surrealismo en" y no al "surrealismo de» Xavier Villaurrutia. Se trata, efectivamente, del entorno desde el que el poeta mexicano edificó su obra, y no la puesta en práctica de una doctrina (que no lo fue) estética o filosófica. En principio, hay dos razones básicas: en primer lugar porque como fenómeno cultural y como postura intelectual el movimiento surrealista no actuó con igual intensidad en París, Madrid o México; en esta última ciudad, pese a la ocasional presencia de algunos de sus fundadores, no tomó el carácter de movimiento ni despertó verdadera actividad literaria . En segundo lugar porque las primeras formulaciones del surrealismo (los manifiestos, sobre todo) no buscaron articular un único y visible derrotero estético, que pudiera hoy denominarse el discurso surrealista ${ }^{2}$.

1. Conviene, sin embargo, atender los estudios sobre el vanguardismo en México, sobre todo en literatura como los de Frank Dauster. Ensayos sobre poesía mexicana: Asedio a los Contemporáneos (México: Ediciones de Andrea, 1963), Merlin H. Forster, Los Contemporósneos: Perfil de un experimento vanguardista mexicano (México: Ediciones de Andrea. 1964), y Luis Mario Schneider, Mérico y el surrealismo: 1925-1950 (México: Arte y Libros, 1978).

2. Sin perjuicio de ello, cfr, nota 19.

Anales de literatura hispanoamericuna, num, I8. Ed. Univ. Complutense, Madrid, 1989. 
Esas dos ausencias hicieron que el movimiento surrealista constituyera para Xavier Villaurrutia una actitud intelectual aparejada por unos temas y contenidos politico-morales. Incluida su generación, Villaurrutia conoció y estudió los alcances del surrealismo en lo que tenía para ćl de atractivo y aprovechable. De ello son testimonio su prosa critica y sus poemas, pero las verdaderas relaciones con el movimiento son poco claras: atracción y reserva son los dos extremos desde los cuales Villaurrutia contempló el movimiento.

En una veintena de páginas es imposible siquiera esbozar los aspectos sustanciales del surrealismo; la copiosa bibliografia sobre el tema aparecida casi desde el instante mismo de la inauguración del movimiento tendrá que sustituir todo intento de sistematización y a ella es preferible remilir. ${ }^{\text {? }}$ Aun así, las consideraciones que siguen tienen tres propósitos: primero. examinar la presencia de aspectos del surrealismo literario en la poesía de Villaurrutia; en segundo lugar, describir su actitud intelectual frente al movimiento, visible en sus ensayos y critica literaria y de arle; y por último, destacar las relaciones que hay entre el movimiento, la cosmovisión del poeta y algunos procedimicntos retóricos de su poesía.

\section{EL ENTORNO ESTETICO-LITERARIO: LA VANGUARDIA Y LOS «CONTEMPORANEOS»}

La obra de Xavier Villaurrutia aparece en medio de diversos intentos por incorporar la literatura mexicana a los movimientos de vanguardia. Por un lado, las influencias de las escuelas de vanguardia (el futurismo, el dadaísmo e incluso el creacionismo) se cohesionaron en el estridentismo, cuya presencia en la poesía mexicana se extiende entre 1922 y 1927 ; y por otro lado, la propia actividad de algunos escritores posteriores, incluido Villaurrutia, que actuaron y escribieron alrededor de algunas revistas literarias (Ulises y Contemporaneos. sobre todo). dan muestra de que el entorno estético-literario de la época buscaba apartarse de la tradición y del regionalismo.

Los primeros poemas de Villaurrutia datan de 1919, pero cronológicamente su primera publicación de importancia es el libro Reflejos (1926), al que siguieron otras más entre 1931 y 1938, reunidas en Nostalgia de la muerte (1938). que amplia en su edición de 1946. Dos anos despues aparece Canto a la primavera y otros poemas (1948). Junto a esa actividad poética escribió (y representó) más de una docena de piezas teatrales entre 1933 y 1950 . y una importante obra critica, dispersa en diarios y revista, que fue reunida

3. De csa amplia bibliografia se han consultado, para cubrir necesidades especificas de este trabajo, los propios escritos de A. Breton, y algunos estudios que han procurado sistematizar la estética y la filosofía del surrealismo. 
en dos tomos: uno por el propio autor, Textos y pretextos (1940), y otro por sus editores, Juicios y prejuicios ${ }^{4}$.

Sin participar directamente en los movimientos de vanguardia, la actividad de Villaurrutia corresponde, sin embargo, a esa época de cambios y réactivación cultural y literaria que siguió al asentamiento de la Revolución Mexicana. La suya fue una generación literaria que se gestó sobre todo alrededor de la mencionada revista Comtemporáneos (México, 19281932). con cuyo mismo nombre se identificó un grupo de poetas como Jorge Cuesta, José Gorostiza. Salvador Novo. Bernardo Ortiz de Montellano, Gilberto Owen, Carlos Pellicer. Jaime Torres Bodet y el propio Villaurrutia 5 . No es difícil encontrar en las páginas de estos escritores (artículos, reseñas, comentarios críticos. etc.) referencias explícitas a sus lecturas, simpatías o conocimiento de los movimientos de vanguardia europeos que por la época estaban en plena actividad. Como lo muestra Luis Mario Schneider. la presencia del surrealismo en México se intensificó a mediados de los años treinta, con la llegada al pais de dos «clásicos»: primero Antonin Artaud (1936) y luego André Breton (1938), quienes cada uno a su manera le otorgaron una particular vigencia a su movimientot.

\section{EL SURREALISMO COMO TEMA: LOS ENSAYOS}

A pesar del amplio conocimiento que Villaurrutia tuvo del surrealismo, sus relaciones directas con el movimiento fueron pocas y marginales. Deben tenerse en cuenta, además, las diferencias cualitativas que hay en sus ensayos y en su poesía con relación al surrealismo. Aunque reconocen la presencia de este movimiento en el escritor mexicano, los estudios críticos fundamentales en torno a la obra de Villaurrutia (Dauster, Debicki, Moretta, Forster, Paz) dedican pocas reflexiones al asunto ${ }^{7}$. Esa relativa mar-

4. Una detallada relación de la historia bibliográfica de Villaurrutia hace Luis Mario Schneider cn la edición que realizó junto con Ali Chumacero y Miguel Capistrán. Ver Xaviee Villaurrutia. Obras: Possia teatro prosas varias critica (Mexico: Fondo de Cultura Económi(a. 1966). especialmente Pp. XXXI-IVIII.

5. La historia de los contemporáneos (c) «grupo sin grupo» según expresión del propio Villaurrutia) la ha tratado con amplitud el profesor Manued Durán en su «Introducción» a $A n-$ rología de la revisa "Contemporáneos" (México: Fondo de Cultura Económica, 1973). pp. 7-51, y en "Contemporáneos": ¿Grupo, promoción, generación. conspiración?", Revista Iberoamericana, XLVIII, 118-119(1982), pp. 37-46. Otros estudios fundamentales para el conocimiento de este conjunto de poetas son los de Frank Dauster y Merlin H. Forster, mencionados en la notà 1 .

6. Cfr. Luis Mario Schncider. México y el surrealismo. De especial interés resulta cl capituIo "El rostro de la táctica» (pp. 107-166), dedicado a la actividad de Bretón en México.

7. Los estudios más importantes que en los últimos años han aparecido son: Frank Dauster. Xavier Villaurratia (New York: Twayne Publishers, Inc., 1971): Andrew P. Debicki, "Xavier Villaurutia: recursos verbales y valores afectivos" en Poetas hispanoamericanos contemporáneos (Madrid: Ectitorial Gredos, 1976), pp. 119-140; Eugene L. Moretta, La poesía de Xavier Villaurrutia (México: Fondo de Cultura Económica, 1976): Merlin H. Forster, Fire and Ice: The Poetry of Xavier Villaumutia (Chapel Hill: University of North Carolina, 1976) y Octavio PaL, Xavier Villaumutia. en persona y en obra (México: Fondo de Cultura Económica, 1978). 
ginalidad, sin embargo, no significó en modo alguno ni indiferencia ni desinterés. No deja de resultar significativo que el apogeo del movimiento en Europa, y posteriormente su inserción en los medios artísticos y literarios mexicanos coinciden con los años en que Villaurrutia escribió lo principal de su obra, es decir, entre 1930 y 1945 aproximadamente.

Entre las prosas tempranas del autor aparece una fechada en 1925 (el mismo año en que se empieza a mencionar el surrealismo en México, según Schneider ${ }^{8}$ ), titulada "Monólogo para una noche de insomnio" ${ }^{9}$. Uno de sus párrafos expresa estas reveladoras ideas del joven escritor, que por entonces contaba con veintidós años:

«Acaso, acaso, frente a tan desoladas perspectivas solamente aparezca con el prestigio de lo desconocido, con vaguedad imprecisa apenas enunciada, el culto metódico, cientifico y regular del sueño.

Vida perfecta la que el sueño proporciona. Vida que consigue, a menudo, el equilibrio entre el descanso del cuerpo y el alama, sosiego del espiritu. inercia del organismo, euforia y ataraxia, ideal griego. Vida también libre y amplia; accidentada y diversa como la esencia del hombren. (p. 604. Excepto las palabras euforia y araraxia, los subrayados son míos. CFM)

Son los mismos años en que redacta y ordena los poemas que habrian de formar el libro Reflejos, en el cual, según se verá más adelante, la ambigüedad entre la realidad y la imaginación es uno de los temas más visibles. $Y$ asuntos surrealistas son también el conocimiento (científico) y las consecuencias del sueño: es decir, el psicoanálisis por un lado, y el deseo de libertad imaginativa (los alcances del arte), por otro.

Xavier Villaurrutia ejerció la "práctica" metódica de lo que por entonces era la moda surrealista en sus años de formación, según se observa en un "Cuaderno" - casi un diario- fechado hacia 1929 que reproducen los recopiladores de su obra ${ }^{10}$. Uno de sus apartados, titulado precisamente "Escritura automática», da cuenta no sólo de la conciencia artística del escritor mexicano, sino también de una decidida voluntad experimentadora que en esos años no parecía pasar de eso, un experimento retórico:

«Se habla, a menudo, de la escritura automática mediúmica Lenormand en ese acto Carmela charla con l'otra |sicl y la pluma no sirve ya raja cola de secante a mi izquierda el puño de la camisa me queda largo el ruido de cristales estrépito de plara que se oye afuera y ya oigo lo que dicen azul y con una linea Agustín Lazo y las mujeres que bordan la estambre de mi corbata la risa la tos acabe ya entiendes...> (p. 618)

8. Cfr, Schneider, México y el surrealismo, p. 4.

9. Cfr. Villaurrutia, Obras, pp. 601-604. En lo sucesivo, bastarán indicar el título del ensayo, prosa o poema, seguidos del ntimero de página, para indicar la procedencia del texto, que siempre provendrá de la citada edición de las Obras de Villaurrutia.

10. Cfr. Villaurrutia, Obras, pp. 616-619. 
Otra prosa, también titulada «Escritura automática» y de fecha cercana a la anterior, da cuenta de dos novedades, aparte de los consabidos procedimientos de escritura; esto es, las alusiones a Breton y el lenguaje autoreferencial de la escritura:

«... porque soy más supersticioso de lo que yo mismo me confieso El bridge de mañana necesito hablar con Alfonso Sánchez No hay que releer nada de lo que se escribe de este modo y no saltan las imágenes como dice Bretón de los Herreros del Covento y los tres mosqueteros de los libros que Marco debe leer y en el colegio dice que no le permiten escribir a sus amigos de fuera. página 34 no sé por qué puse una coma en la comida de mi tio de cabeza blanca...n (p. 621)

La reflexión y la critica en torno al surrealismo las empezó a desarrollar Villaurrutia a partir de 1930, en numerosos artículos de prensa, reseñas, comentarios, ensayos o conferencias. De la veintena de ensayos que componene Textos y pretextos destaca uno escrito a finales de 1930 y leido en la sesión inaugural de una exposición pictórica: "Pintura sin mancha». Varios aspectos característicos de las posturas del movimiento son visibles en el ensayo: las relaciones entre las artes plásticas (la pintura, sobre todo) y las artes literarias; el arte como rebasamiento del conocimiento racional y en consecuencia sus vinculaciones con la actividad onírica; la posibilidad de poner en relación actividades o entidades diversas. Estos tres aspectos dan cuenta del conocimiento - y en algunos instantes de la simpatia- que Villaurrutia tenía de la evolución artística de la época y que en muchos sentidos cohesionó el movimiento surrealista. En «Pintura sin mancha» se sostiene la capacidad que tiene el arte de conocer el mundo con procedimientos que van más allá de lo racional:

"La lectura de un poema o la contemplación de un cuadro vivientes os darán, mejor que nada, esa consciencia de lo impensable que el razonamiento no alcanza a producir, mucho menos a entregar.m (p. 742)

Para Villaurrutia (como para los surrealistas) es posible un arte que supere los convencionalismos del conocimiento racional, y así las separaciones radicales pueden desaparecer:

"Pero el artista sigue viviendo en equilibrio inestable en un punto peligroso entre dos abismos. el de la realidad que lo circunda y el de su realidad interior... La realidad contiene al hombre y todo el contenido del hombre es realidad. El artista de ahora parece no contentarse con una sola de estas realidades. Ni la exterior ni la interior le bastan separadamente. Y expresar sólo una de ellas implica renunciar a la otra. Me pregunto ¿de qué modo ha de expresar las dos realidades si median entre ellas las paredes de los vasos que las contienen? Destruyendo estas paredes 0 , mejor, haciéndolas invisibles y porosas para lograr una filtración, una circulación, una transfusión de realidades». (p. 742) 
Este conjunto de nociones lo llevan a una creencia cuyas raices bien podrian tener que ver con el esoterismo, aunque su fuente más inmediata es precisamente una práctica literaria que rechazaba la obviedad del realismo. La critica al conocimiento cartesiano conducia a Breton (en 1924) y a Villaurrutia (en 1930) a una idea de la actividad artística como vía de conocimiento sintético y suprarracional. Compárense sendos textos de estos escritores:

"So pretexto de civilización-decía Breton en su Primer Manifiesto-, con la excusa del progreso, se ha llegado a desterrar del reino del espiritu cuanto pueda calificarse, con razón o sin ella, de superstición o quimera; se ha llegado a proscribir todos aquellos modos de investigación que no se conformen con los usos imperantes»."

"Yo pienso que el objeto de la música es hacer oír lo inaudito, expresando cuanto hay de significativo en el ruido y en el ruido que hace silencio, y que si el fin de la poesia es hacer pensar en lo impensable, acaso el objeto de la pintura no sea otro que hacer ver lo invisible.

¡Hacer ver lo invisible! Operación mágica, operación religiosa, operación poética. Denominador común de todas las artes es la poesía: 'substancia de las cosas inesperadas, evidencia de las cosas no vistas'» («Pintura sin mancha», p. 745)

Un desarrollo mayor de sus ideas en torno al surrealismo como actitud filosófica y como posibilidad estética está presente en otros escritos, casi todos reunidos en Juicios y prejuicios. Uno de ellos, escrito hacia 1924. titulado «La poesia de los jóvenes de México», revela un primer conocimiento de los movimientos europeos de vanguardia; al referirse a un compatriota suyo dice: «Manuel Maples [Arce] supo inyectarse, no sin valor, el desequilibrado producto europeo de los ismos" (p. 827, subrayado mio). Su conocimiento de la escritura automática también fue objeto de reflexiones sobre estética; en una carta al poeta Bernardo Ortiz de Montellano, verdadero ensayo de crítica literaria. dice:

«Juega usted con ellas [las palabras\} cuando, enamorado de su ruido, rompe usted la presión y en consecuencia la unidad de su estrofa y en consecuencia la unidad de su poema. Juegan con usted cuando, en un desmayo, acaso voluntario, de su atención se entrega a lo que podemos llamar una escritura poética automática» ( UUna botella al mar», pp. 838839)

El ensayo con que se abre Juicios y prejuicios, «Introducción a la poesía mexicana», escrito hacia 1940, es decir, cuando algunos de los poetas del grupo Contemporáneos habían dado sus obras fundamentales, es una

11. André Breton. Manifiestos del surrealismo (Barcelona: Ediciones Guadarrama. 1985), p. 25 . 
muestra de la importancia que el movimiento surrealista tuvo para aquellos poetas mexicanos, al menos como punto de referencia ${ }^{12}$. En ese ensayo es manifiesta la lectura de los surrealista franceses, y en todo caso la acogida de varios rasgos fundamentales de la poesia más reciente. Villaurrutia defiende la coexistencia del irracionalismo en el arte y el control de la conciencia por parte del artista, pero al mismo tiempo sostiene la importancia del sueño y la actividad onírica en general como verdaderos motores para alcanzar la libertad expresiva y con ella la existencial. Esto muestra que Villaurrutia no completó el círculo de la experiencia surrealista, sino que la tomó como patrón poético y filosófico desde cl que ajustó y enriqueció su propia manera de ejercer la poesía. La desconfianza en el abandono a las alucinaciones y al descontrol la atribuye Villaurrutia, quizá ingenuamente, a una condición étnica del mexicano, aunque no por ello renuncia a reconocer las enormes posibilidades que para el desarrollo artístico, moral y filosófico tienen estas dimensiones de la condición humana. El análisis de la poesía mexicana de su tiempo (o dicho más claramente, de su grupo) es en cierta medida una lectura comentada de los manifiestos bretonianos:

«El irracionalismo, el automatismo de las nuevas escuelas poéticas, no ha entrado con la fuerza invasora que ha entrado en otras cosas, por la razón de que el mexicano en un ser reducido cuya embriaguez mayor consiste precisamente en mantenerse lúcido y que, aun a la hora de soñar, gusta de mantenerse despierto.

En estos momentos en que la poesía va tomando varias formas, unas veces en el abandono más puro y otras veces en esta atención, en esta espera profunda, los poetas mexicanos han tenido presente, no han desdeñado la corriente del irracionalismo, las conquistas de lo anímico, del sueño. Antes bien, han asimilado estas nuevas posibilidades, estas nuevas aportaciones de esta forma de libertad. Pero los poetas mexicanos, por el hecho de serlo, aun dentro del sueño, se mantienen en vigilia, en una vigilia tremenda.» («Introducción a la poesía mexicana», p. 772)

Esta oscilación entre los estados de fantasía y los de lucidez, o dicho en palabras del poeta «el equilibrio inestable en un punto peligroso entre dos abismos», es la base de su propia teoría poética. Uno de los temas frencuentes de su poesía es el movimiento pendular entre los estados del sueño y la vigilia, entre el soñar despierto y el vivir soñando. Esto es motivo de reflexiones estéticas, referidas no solo a su propia obra, sino también a su generación. a la poesía de su país, y al desarrollo de la poesía contemporánea en lengua española. De esta última decia:

12. Ortiz de Montellano habia publicado Muerte del cielo azul (1937). Villaurrutia Nostalgia de la muerte (1938), Gorostiza Muerte sin fin (1939), Pellicer Hora de junio (1937) y Salvador Novo habia editado unas Poesias escogidas (1938). 
«El mundo del subconsciente, las preocupaciones oníricas y aun cierto automatismo poético irrumpetl ahora, francamente, en la poesía moderna de lengua española y adoptan diversas caracteristicas en España y en América

Conviene, pues, tener presente que, sin desdenar la corriente de irracionalismo, antes bien asimilando las nuevas posibilidades y aportaciones de esta forma de libertad, otros espiritus se mantienen -aún dentro del sueño- en una vigilia, en una vigilancia constantes". ("La poesia moderna en lengua española», p. 880 . Subrayados mios)

Y refiriéndose a la obra de un poeta de su generación (Ortiz de Montellano) sostenia:

«Sólo la mano de un vivo puede escribir el poema del sueño. Conviene. pues, que el poeta que ha optado por esta segunda y única manera artistica, no permita que la mano se le duerma.» («Una botella al mar», p. 389)

Tal es una de las diferencias centrales que separan a Villaurrutia de la ortodoxia surrealista ${ }^{13}$. Para el poeta mexicano las obras artisticas (literarias o plásticas) están en capacidad de mostrar los mundos de la alucinación, la magia o el misterio, aunque no necesariamente con procedimientos alucinantes o escrituras delirantes. Una cosa es el mundo alucinado que actúa de contenido artístico, y otra muy distinta el control lúcido y racional que el artista ejerce para manifestar ese mundo. Eso vale para la pintura y para la poesía. La obra del pintor Alfaro Siqueiros es, según Villaurrutia, un caso ejemplar puesto que consigue destruir las diferencias entre el mundo exterior y el interior, y además da cuenta de mundos insospechados, sin renunciar a la coherencia estética a través del trabajo consciente:

"Y la misión del artista e: algo mucho más complejo que se ejerce no sólo por medio del hallazgo de un vehiculo entre el modelo exterior y la habilidad manual, sino por caminos más recónditos y profundos porque son interiores.. Sólo unos cuantos pintores han hecho algo más que transladar [sic] o reconstruir el mundo de incitaciones que fuera de ellos se presenta a su vista. Estos pintores han enriquecido con visiones inesperadas y nuevas, salidas del sueño, de la alucinación y del deseo confesadio, el mundo, añadiendo a la realidad cotidiana fragmentos de realidad interior no menos intensos y más profundos. Estos pintores han sido muchos más hábiles obreros, puesto que han sido, en verdad, creadores, inventores». ("David Alfaro Siqueiros", p. 1031)

13. En cl primer Manifiesto Breton decia: "Creo en la futura armonización de estos dos estados. aparentemente an contradictorios, que son el sueño y la realidad. en una expecie de realidad absoluta, en una sobrerrealidad o surrealidad. si así se le puede llamar». (Manifisstos del surrealismo. p. 30). 
Muchos otros ensayos mantienen y desarrollan estas ideas básicas: «La poesía de Nerval», «Fichas sin sobre para Lazo», «Lectura en una exposición», "Meditación ante un retrato», «Moreno Villa», etc. En ellos son visibles: la importancia cualitativa que el movimiento surrealista habia tenido en el desarrollo del arte de entonces; la posibilidad de dar cuenta de los mundos interiores; la capacidad imaginativa del ser humano; el arte como vía de conocimiento; la realidad onírica como tema y como viaducto cosmovisionario. Junto a ellos una preocupación marginal: la desproporción entre la riqueza de contenidos de la filosofia surrealista y el escaso desarrollo de un estilo (un discurso) surrealista, aparte de la conocida «escritura automática" de la que tanto desconfió Villaurrutia.

El reconocimiento del poeta mexicano por el movimiento fue, sin embargo, intenso y continuo. Muchas obras surrealistas llegaron a sus manos y las promocionó con entusiasmo en México: en 1938 escribió un comentario sobre El perro andaluz de Buñuel; en la revista Letras de México de mayo de ese mismo año aparecieron dos traducciones suyas: «Un hombre y una mujer absolutamente blancos» de André Breton y «La enamorada» de Paul Eluard; en 1942 escribió un "Prólogo" a una traducción de Aurelia de Gerard de Nerval, y al año siguiente hizo una reseña para la revista El hijo pródigo de México de "Le Chateau de Grisou» de César Moro ${ }^{14}$. Fueron los años en que el surrealismo habia dejado de ser percibido como una moda (como en cierto sentido lo creia Villaurrutia quince años antes); era ya un movimiento de mayor envergadura que rebasaba incluso la problemática de lo estético y que el poeta mexicano lo entendia como una realidad cultural de Occidente de amplio alcance. De ello es testimonio una singular encuesta que la revista mexicana Romance hizo entre febrero y marzo de 1940 a los intelectuales de la época. Una de la preguntas decía: «,Cómo definiria usted las características de la literatura posterior al movimiento surrealista?». Villaurrutia respondió así:

«Al hablar de la literatura posterior al movimiento surrealista, la pregunta implica que este movimiento llegó a su fin y que es ya un límite. Niego. La literatura actual se ha enriquecido con las preocupaciones, con las experiencias, con las filiaciones suprarrealistas. Tiende a una expresión total del hombre, del hombre interior, del hombre que el hombre ha ido ocultando en el hombres. 15

El asentimiento creciente que Villaurrutia mostró por el movimiento quedó incorporado, como es de suponer, a un sistema de valores artístico y filosófico que tomó forma tanto en sus articulos críticos como en su teatro y en su poesia. Esta última resultó especialmente sensible a los aportes que el movimiento como cosmovisión significaba para el poeta.

14. A todo esto se refiere con detalle Schneider, op. cit., pp. 237-246.

15. Citado por Schncider, op. cit., pp. 184-185. 


\section{ELEMENTOS DEL SURREALISMO EN LA POESIA}

Postulando el surrealismo como una postura ante el mundo, es decir, como una verdadera cosmovisión cuyas derivaciones se dieron en el plano artistico principalmente, es evidente que la obra poética de Villaurrutia no participó directamente del movimiento ni con ella dio muestras de una voluntad rigurosamente vanguardista en el contexto de la lírica mexicana. El inventario de sus ideas y reflexiones en torno al surrealismo da cuenta de su atención y conocimiento de las posibilidades y alcances del movimiento. La distancia que mantuvo entre aquel acontecer cultural originado en Europa y el desarrollo de su propia actividad literaria supone que el surrealismo fue para el mexicano - también en su poesia- una sustancia inicial con algunos de cuyos ingredientes amplió su propia experiencia ante el mundo.

Como en los ensayos y prosas criticas, hay visibles coincidencias y acercamientos entre los temas, motivos y «filosofia» surrealistas y la visión de mundo organizada en la poesía de Reftejos, Nostalgia de la muerte o Canto a la primavera. Hay, además, algunos aspectos de su retórica poética emparentables con la escritura surrealista que en cierto sentido corresponden a la congruencia literaria que en su obra (sobre todo en su poesía) Villaurrutia siempre buscó. Documentada profusamente, su preocupación por el control racional y la construcción esmerada de los textos, si bien se separa mucho de la ortodoxia surrealista, da cuenta de un conjunto de recursos retóricos que contienen aspectos medulares de la modalidad surrealista.

Aunque quizá resulte simplificador de las verdaderas dimensiones y alcances del surrealismo, baste detenernos en tres aspectos básicos de la poesía de Villaurrutia que la enlazan con el movimiento: 1) la experiencia de la actividad onírica, 2) el erotismo como tema y 3) la creencia en la abolición de entidades o nociones opuestas. Las ramificaciones temáticas y las relaciones de interdependencia de esos tres grandes núcleos en su poesia son el objeto de las consideraciones que siguen.

El tema del sueño, y su concomitante tema de la noche, es el más visible en la poesía de Villaurrutia, como lo pueden mostrar sus conocidos y numerosos "Nocturnos", estudiados con singular atención por la crítica ${ }^{\text {th }}$. Sin embargo, de esto ya hay antecedentes en Reflejos, su libro de 1926, en el que enuncia un asunto central en su poética: la ambigüedad entre el sueño y la vida:

«Nos juntó un sueño

En el suerio rodábamos

como en un prado fresco.
¿Nos juntará la vida

como el sueñom?

(«Sueñom, p. 27)

16. Hay que tener en cuenta que antes de ser reunidos en el libro Nosfalgia de la muerte. muchos de los "noctumos" aparecieron como publicaciones independientes, a saber: Dos noctumos (1931), Noctumos (1931), Noctumo de los ángeles (1936) y Noctumo mar (1937). De los estudios críticos se da cuenta en nota 7 . 
De esta primera noción deriva no tanto el tema del sueño como el tema de la vacilación misma que tal estado de la inteligencia provoca. En Nostalgia de la muerte el sueño queda asociado al cambio, la inconsistencia o el equivoco:

"Prisionero de mi frente

el sueño quiere escapar

No sabe que soy el sueño

de otro...s

( (Nocturno preso", p. 49)

«iY dudo! Y no me atrevo a preguntarme si es

el despertar de un sueño o es un sueño mi vida».

(«Estancias nocturnas», p. 62)

Y de modo semejante en poemas de Canto a la primavera:

"Pero amar es también cerrar los ojos.

dejar que el sueño invada nuestro cuerpo

como un río de olvido y de tinieblas»

("Amor condusse noi ad una morte», p. 77)

«Nada quieras saber de mi pasado.

Despertar es morir. ¿No me despiertes!?

(«Epitafios», p. 90)

Esta ambigüedad lleva también al tema de los mundos alucinantes, en los que las oposiciones entre lo real y lo imaginado, por ejemplo, son puestas en duda. Ello explica no sólo la técnica de la asociación libre de ideas sino también las analogias inusitadas en la realidad exterior. Sin llegar a la escritura atomática, el libre fluir de conciencia del poema «Nocturno amor» es un ejemplo de que el mundo es caos y relaciones inesperadas entre los elementos de la realidad:

«El que nada se oye en esta alberca de sombra no sé cómo mis brazos no se hieren cn tu respiración sigo la angustia del crimen

y caes en la red que tiende el sueño Guardas el nombre de tu cómplice en los ojos pero encuentro tus párpados más duros que el silencio y antes de compartirlo matarias el goce de entregarte en el sueño con los ojos cerrados sufro al sentir la dicha con que tu cuerpo busca el cuerpo que te vence más que el sueño y comparo la fiebre de mis manos con mis manos de hielo"

(«Nocturno amor», pp. 49-50) 
Esta "poética del sueño», uno de los principios fundamentales del surrealismo, da origen también a las prácticas artisticas que formalizan las tendencias irracionales, la presencia de mundos extraños, y la idea de que el lenguaje puede ser capaz de simbolizar adecuadamente las relaciones entre los mundos interior (psique) y exterior (realidad). Desde este punto de vista, para los surrealistas la palabra fue lugar de experimentación y posibilidad de simbolizar mundos extralógicos. Aunque hubiera compartido sus ideales, Villaurrutia no participó siempre de este proyecto; en la experiencia poética la palabra no siempre resultó develadora. sino más bien lo contrario, o en todo caso, incapaz de dar cuenta cierta de la realidad buscada. Esta circunstancia es tema frecuente en su poesía:

«Te forman las palabras

que salen del silencio

y del tanque del sueño en que me ahogo

libre hasta despertarn.

(«Poesia», p. 26)

«... la cólera circula por mis arterias

amarilla de incendio en mitad de la noche

y todas las palabras en la prisión de la boca

y una sed que en el agua del espejo

sacia su sed con una sed identica»

(«Nocturno amot», p. 50)

«porque vida silencio piel y boca

y soledad recuerdo cielo y humo

nada son sino sombras de palabras

que nos salen al paso de la noches

( Nocturno eterno", p. 52)

«Palabra quen sabes lo que nombras.

Palabra, ireina altiva!

Llamas nube a la sombra fugitiva

de un mundo en que las nubes son las sombrass.

(«Palabra», p. 85)

La búsqueda de esta «otra realidad», presenciada en los sueños y por los procedimientos de la irracionalidad, está relacionada no únicamente con el mundo de lo oculto, sino también con el mundo del otro ser (de la «otredad»), y a partir de ello con la complejidad de la comunicación amorosa: el erotismo. Para Villaurrutia el valor del erotismo consiste en ser una operación que une simbólicamente los mundos separados y distantes. Desde tal punto de vista sus coincidencias con la moral surrealista son sustanciales. Como cl acto poético, el crotismo es nostalgia de comunicación: 
«Si cada uno dijera en un momento dado, en sólo una palabra, lo que piensa, las cinco letras del DESEO formarian una enorme cicatriz luminosa, una constelación más antigua, más viva aún que las otras.

Y esa constelación sería como un ardiente sexo en el profundo cuerpo de la noche.

$o$, mejor, como los Gemelos que por primera vez en la vida se miraran de frente, a los ojos, y se abrazaran ya para siempre"

(«Nocturno de los ángeles», p. 55)

«Y sobre tu cuerpo blando mis labios iban dejando huellas, señales, heridas... $Y$ tus palabras transidas $y$ las mias delirantes de aquellos breves instantes prolongaban nuestras vidas."

(«Décimas de nuestro amor», p. 81)

«si juntos nuestros labios desnudos como cuerpos. y nuestros cuerpos juntos como labios desnudos no formaran un cuerpo y una respiración. ino fuera amor el nuestro, no fuera nuestro amor!?

(Idem, p. 83)

Los vinculos entre poesía y erotismo corresponden en toda su extensión a los versos transcritos del poema "Nocturno de los ángeles»: «las cinco letras del DESEO formarian una enorme cicatriz luminosa" (subrayado del autor), y las raices de esa creencia también se hallan en el primer Manifiesto, en el que Breton subraya:

«El hombre proponc y dispone. Tan sólo de él depende poseerse por entero. es decir, mantener en estado de anatquia la cuadrilla de sus deseos, de dia en dia más temible. Y esto se lo enseña la poesia. La poesia lleva en si la perfecta compensación de las miserias que padecemosm.17

Poesía y erotismo, palabra y deseo son formulaciones que explican en buena medida la red temática de la poesia de Villaurrutia. Lo que destaca en ella es la presencia recurrente de un conjunto de motivos relacionados entre si: el sueño, la alucinación, la noche, la búsqueda de otra realidad, la presencia del otro, el deseo de comunicación, el erotismo, el amor, la disolución del ser individual, la muerte. La experiencia de la actividad poética

17. Bretón, Manificstos del surrealismo, p, 35 
se constituye, asi, en el testimonio del deseo y de la irrealidad de lo deseado. Dentro de esa circunstancia se explica la noción siguiente:

«Si empezara a decirlo con fantasmas

de palabras y engaños, al azar,

llegaría, temblando de sorpresa

a inventar la verdads

(«Inventar la verdad», p. 84)

Conciencia de la otredad, deseo de comunicación y erotismo se asocian al tercer aspecto que aquí hemos de examinar: la abolición de los contrarios ${ }^{18}$. En el caso de Villaurrutia esta abolición es sólo especulación y en consecuencia duda, que a su vez produce angustia. De nuevo se hace presente el tema de la ambigüedad, y su relación con la configuración de mundos vacilantes, enigmáticos o indeterminados: la realidad onirica, la imaginación, el delirio, la noche, las calles oscuras, las zonas crepusculares, la sombra. De entre los múltiples casos, se puedan transcribir algunos ejemplos de los singulares efectos emotivos que despierta el contacto de realidades opuestas:

"Asi, robando la luz, seguimos sin llegar

y sin partirn.

(《Viaje», p. 39)

"Todo en la noche vive una duda secreta:

el silencio y el ruido, el tiempo y el lugar.

Inmóviles dormidos o despiertos sonámbulos

nada podemos contra la secreta ansiedadr.

(«Nocturno miedo", p. 45)

«La sombra es silenciosa, tanto que no sabemos

donde empieza o acaba, ni si empieza o acaban.

(«Nocturno», p. 53)

"[...] su movimiento

es una misteriosa forma de la quietud».

(«Nocturna rosa», p. 57)

18. Este principio es fundamental para el movimiento surrealista. En el segundo Manifiesto, Bretón afirmaba: «Se trata [...] de atacar por todos los medios, y procurar que se reconozea a todo precio, el engañoso carácter de las viejas antonimias hipócritamente destinadas a impedir cualquier insólita inquietud humana [...]. Todo induce a creer que en el espíritu humano existe un cierto punto desde el que la vida y la muerte, lo real y lo imaginario, el pasado y el futuro, lo comunicable y lo incomunicable, lo alto y lo bajo, dejan de ser vistos como contradicciones". (Manifiestos del surrealismo, p. 162).

Por otra parte, resulta significativo que Villaurrutia tradujo y publicó en 1929 Matrimonio del cielo y el infierno de Blake. Cfr. el dato, aportado por L. M. Schneider en Villaurrutia. Obras, p. XXXIII. 


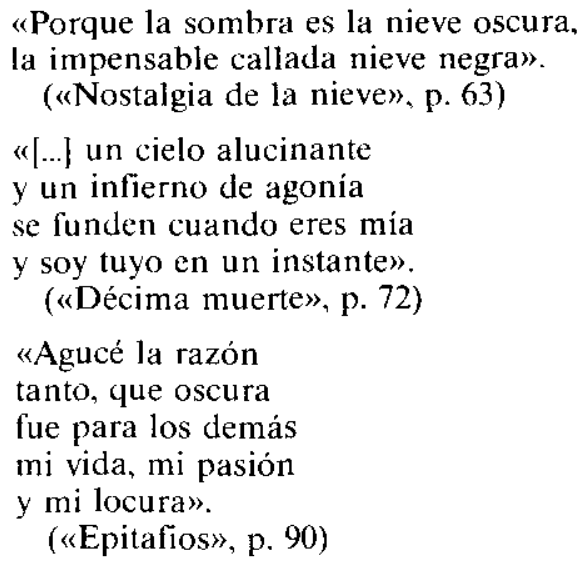

Al mismo tiempo la abolición de los contrarios significa la abolición (o la duda) de las diferencias entre el yo y los otros, entre la propia identidad y la ajena. Como tema, es uno de los más frecuentes y visibles en la poesía de Villaurrutia, y está en directa relación con el reconocimiento de otrá realidad como posibilidad ontológica y cognoscitiva. La distinción racional entre la objetividad y la subjetividad se desplaza y con ello se favorece la imprecisión de los signos del mundo, noción tan cara a Villaurrutia. El desdoblamiento. la confusión entre el yo y una entidad ajena, la duda, la suplantación y el deseo de cambiar la identidad original constituye el abanico de opciones temáticas en una poesía que es el resultado de una visión de mundo compartida generacionalmente. Al margen de las causas históricas inmediatas que estimulan esta postura $-y$ sobre las que por razones de espacio y de oportunidad no cabe detenernos en estas páginas- esta problemática fue para Villaurrutia objeto de una formulación de carácter más filosófico que literario: el reconocimiento de la existencia de los otros es la raiz de la duda en la propia existencia. Así, el tema de la otredad fluye en muchas direcciones:

«Y cuando lloro - algunas veces llorotambién sus ojos se humedecen o será que los miro con los míos".

(«Soledad", p. 41)

«Caminar sin que los espejos

me pongan enfrente.

itan parecido a mi!n

(«Calles», p. 41)

«El miedo de no ser sino un cuerpo vacio

que alguien, yo mismo o cualquier otro, puede ocupar,

y la angustia de verse fuera de si, viviendo,

y la duda de ser o no ser realidadm.

( «Nocturno miedon, pp. 45-46) 
« ¿Será mía aquella sombra

sin cuerpo que va pasando?

(«Nocturno grito", p. 46)

"Y al oprimir la pluma,

algo como la sangre late y circula en ella.

y siento que las letras desiguales

que escribo ahora.

más pequeñas, más trémulas, más débiles.

ya no son de mi mano solamente".

( (Nocturno en que habla la muerte», p. 55)

"Siento miedo de que no sea sino el eco

de otros pasos ajenos, que pasaron mucho antes".

( Estaciones nocturnas", p. 62)

«el miedo de dejar de ser uno mismo

ya para siempre,

ahogándose en un mundo

en que ya las palabras y los actos

no tengan el sentido que acostumbramos darles"

(«Paradoja del miedo», p. 68)

"porque mi muerte es tu muerte."

( (Décimas de nuestro amor», p. 79)

Examinadas estas tres grandes tendencias caracteristicas del surrealismo (la poética del sueño, el erotismo, la abolición de los contrarios), conviene mencionar en forma necesariamente breve algunos aspectos de la escritura en la poesia de Villaurrutia que están en correspondencia con la visión de mundo descrita, y que además guardan relaciones significativas con diversos procedimientos que también caracterizaron la estética literaria surrealista ${ }^{19}$. Salvo escasisimos momentos, no es la escritura automática el centro de atención de la poesía de Villaurrutia y menos aún un procedimiento sistemático. Si para el surrealismo la escritura automática fue un método de liberación del pensamiento, y no un rasgo de una posible estética literaria, para Villaurrutia lo fue aún menos: fue un experimento formal que apenas puso en práctica en su poesía. No obstante, varios aspectos estilísticos y recursos retóricos en general frecuentes en su obra están emparentados con el fondo de la actitud surrealista, y en consecuencia dio por resultado un discurso poético cercano al movimiento.

Tomados en su conjunto, muchos de los procedimientos a los que acu-

19. Son pocos los estudios dedicados a los procedimientos propiamente literarios de las obras poéticas surrealistas, por lo menos a la escrita en lengua espanola. Aparte de ello. como se sabe, la ortodoxia surrealista no prestó mayor atención al problema. toda vez que el surrealismo, scgún Bretón afirmaba, estaba «ajeno a toda preocupación estética o moral" (Manifiestos, p. 44). Pese a lo dicho, por estar dedicado al surrealismo y a los procedimientos literarios que los caracterizan es fundamental el tratado de Carlos Bousoño Superrrealismo poético y simbolización (Madricl: Editortal Gredos, 1979). 
de Villaurrutia se vinculan con los modos de expresión sustentados en el irracionalismo. En el plano semántico la deliberada y sistemática ruptura con la lógica, el acercamiento de semas opuestos, las incongruencias o contradicciones asumidas como posibilidades de sentido son, entre otros, los rasgos más visibles del discurso poético de Villaurrutia. El absurdo, el contrasentido o el equívoco son portadores de significado y ello es uno de los puntos de partida del mundo poético del escritor mexicano, y los recursos literarios así lo formalizan:

«De prisa, dejando atrás la compañía

eterna, hasta quedarme solo.

solo, sin soledad.s

("Calles". p. 4l)

"Mi pecho estará vacio

y yo descorazonado»

( (Nocturno grito", p. 46)

"acariciarla como a una hermana imprevista

y jugar con las fichas de sus dedós

y contar a su oreja cien veces cien cien veces

hasta oírla decir: "estoy muerta de sueño"”.

( «Nocturno de la estatua», p. 47)

«Abria las salas

profundas el sueño

Cerraba las alas

profundas el sueño».

("Nocturno sueño", pp. 48-49)

"Mar sin viento ni cielo.

sin olas, desolado»,

("Nocturno mar», p. 59)

"siento que estoy en el infierno frío

en el invierno eterno»

("Muerte en el frío", p. 67)

"Amarte con fuego duro y frío.

Amarte sin palabras, sin pausas ni silenciosn.

(«Deseo», p. 84)

«Es inútil mi fiebre de alcanzarte,

mientras tú mismo, que todo lo puedes

no vengas a mis redes a enredarte».

( «Soneto del temor a Dios», p. 85)

A esto se asocia un procedimiento estilístico muy comentado y destacado por la critica a la obra de Villaurrutia y comentada en alguna ocasión por el mismo escritor: los denominados en un sentido lato juegos de palabras, pero que en realidad son entre otros la disemia, la paronomasia, la 
correlación y el paralelismo, como lo ha mostrado con amplitud César Rodriguez Chicharro ${ }^{20}$. Con ellos la operación sentido/sinsentido, la ambigüedad o las sorpresas semánticas rebasan claramente el ingenio o el puro juego de lenguaje. Obsérvense los casos más conocidos y citados:

"me estoy mirando mirarme por mil Argos.

por mi largos segundos».

(«Poesia", p. 26)

"Y en el juego angustioso de un espejo frente a otro

cae mi voz

y mi voz que madura

y mi voz quemadura

y mi bosque madura

y mi voz quema dura

(«Nocturno en que nada se oye», p. 47)

«Cuando los hombres alzan los hombros y pasan

o cuando dejan caer sus nombres

hasta que la sombra se asombra"

( «Nocturno eterno». p. 51)

«cuando la vi cuando la vid cuando la vida»

(Idem, ídem)

«QQuién medirá el espacio, quién me dirá el momento

en que se funda el hielo de mi cuerpo»

("Nocturno muerto", p. 52)

Más que libertad expresiva, en la poesía de Villaurrutia se da la libertad asociativa. lo que explica tanto el culto al sueño como toda referencia a contrastar y poner en relación a la vez las realidades evidentes y las encubiertas, las ambivalencias, la imaginación, el azar, el deseo o la alucinación. "Ver lo invisible» (cfr. supra) es la cualidad central de la actividad artística y poética, pero no llega a emparentarse con la arbitrariedad o el abandono expresivos. La dualidad sueño/vigilia, en la que se detiene con frecuencia en sus reflexiones sobre estética y poesía, adquiere cuerpo en su práctica literaria: el lenguaje es para el poeta un instrumento mágico y un instrumento lógico; da cuenta de mundos imprevistos y además permite que el poeta no se abandone al delirio y a la incomunicación ${ }^{21}$. No es ocasional por ello el hecho de que buena parte de la producción poética de $\mathrm{Vi}$ llaurrutia esté adscrita a formas canónicas tradicionales: poemas en cuartetos rigurosamente construidos, sonetos, pareados, redondillas, décimas,

20. Cfr. César Rodriguez Chicharro, «Disemia y paronomasia en la poesia de Xadvier Villaurrutia", La palabra y el hombre, 30 (1964), pp. 249-260 y "Correlación y paralelismo en la poesia de Xavier Villaurrutias, La palabra y el hombre, 37 (1966), pp. 81-90.

21. Dice Villaurrutia: «En manos del poeta - y sólo en sus manos- el lenguaje no es sólo un instrumento lógico sino también un instrumento mágico» («Introducción al rigor». Obras. p. 297). 
conjuntos poemáticos de versos alejandrinos, endecasilabos, heptasilabos, uso de la rima, etc.

Los sucesivos acercamiento y distancia que puso Villaurrutia entre su poesia y el movimiento surrealista pueden tener una primera explicación: la actitud antidogmática, frente a la politica y frente a la estética, que los Contemporáneos (es decir, su generación) asumieron casi siempre. En cualquiera de los casos, el surrealismo no dejó de ser un factor de primordial importancia tanto para la formación estético-literaria de Villaurrutia y de algunos de su "grupo sin grupo», como para la configuración de una visión de mundo ocupada en descifrar al mismo tiempo un momento histórico y un devenir con cambios morales y filosóficos de mayor envergadura.

Carlos Francisco Monge Universidad Nacional Heredia (Costa Rica) 